\title{
Nonlocal boundary value problems of fractional order at resonance with integral conditions
}

\section{Hai-E Zhang*}

${ }^{\text {*Correspondence: }}$
haiezhang@126.com
Department of Basic Teaching,
Tangshan University, Tangshan,
Hebei 063000, People's Republic of
China

\begin{abstract}
Based upon the well-known coincidence degree theory of Mawhin, we obtain some new existence results for a class of nonlocal fractional boundary value problems at resonance given by

$$
\left\{\begin{array}{l}
D_{0+}^{\alpha} u(t)=f\left(t, u(t), D_{0+}^{\alpha-1} u(t), D_{0+}^{\alpha-2} u(t)\right), \quad t \in(0,1) \\
\beta_{0^{+}}^{-\alpha} u(0)=u^{\prime}(0)=0, \quad D_{0+}^{\beta} u(1)=\int_{0}^{1} D_{0+}^{\beta} u(t) d A(t)
\end{array}\right.
$$

where $\alpha, \beta$ are real numbers with $2<\alpha \leq 3,0<\beta \leq 1, D_{0+}^{\alpha}$ and $l_{0+}^{\alpha}$ respectively denote Riemann-Liouville derivative and integral of order $\alpha, f:[0,1] \times \mathbb{R}^{3} \rightarrow \mathbb{R}$ satisfies the Carathéodory conditions, $\int_{0}^{1} D_{0+}^{\beta} u(t) d A(t)$ is a Riemann-Stieltjes integral with $\int_{0}^{1} t^{\alpha-\beta-1} d A(t)=1$. We also present an example to demonstrate the application of the main results.
\end{abstract}

MSC: $34 \mathrm{~B} 15$

Keywords: fractional differential equation; resonance; Riemann-Stieltjes integral; coincidence degree theory

\section{Introduction}

In recent years, fractional calculus theory has become a popular area of investigation in view of its widespread applications. Furthermore, fractional differential equation, as a branch of fractional calculus, has been a hot area of research of differential equation with not only numerous theoretical developments, but also countless applications to practical problems. For example, in order to describe certain problems raised in science and engineering, the fractional differential equation is superior to the classical integer one, especially in the fields of biology, physics, mechanics, ecological engineering, finance and other fields which propose the process of memory and genetic properties. For more details about fractional differential equations, one can see [1-4].

In the past few years, fractional differential equations have attracted a considerable attention because of their extensive applications in realistic modeling. Consequently, a variety of excellent results on fractional boundary value problems (abbreviated BVPs) with resonant conditions have been achieved. For instance, we recommend [5-13] to the read-

(c) The Author(s) 2017. This article is distributed under the terms of the Creative Commons Attribution 4.0 International License (http://creativecommons.org/licenses/by/4.0/), which permits unrestricted use, distribution, and reproduction in any medium, provided you give appropriate credit to the original author(s) and the source, provide a link to the Creative Commons license, and indicate if changes were made. 
ers and the references therein. It is worth mentioning that Bai [7] studied a type of fractional differential equations with m-points boundary conditions (abbreviated BCs)

$$
\left\{\begin{array}{l}
D_{0_{+}}^{\alpha} u(t)=f\left(t, u(t), D_{0+}^{\alpha-1} u(t)\right)+e(t), \quad t \in(0,1), \\
\left.I_{0^{+}}^{2-\alpha} u(t)\right|_{t=0}=0, \quad u(1)=\sum_{i=1}^{m-2} \beta_{i} u\left(\eta_{i}\right),
\end{array}\right.
$$

where $1<\alpha \leq 2$. The existence of nontrivial solutions was established by using coincidence degree theory. Applying the same method, Kosmatov [10] investigated the fractional order three points BVP with resonant case

$$
\left\{\begin{array}{l}
D_{0+}^{\alpha} u(t)=f\left(t, u(t), D_{0+}^{\alpha-1} u(t)\right)+e(t), \quad \text { a.e. } t \in(0,1), \\
D_{0^{+}}^{\alpha-2} u(0)=0, \quad \eta u(\xi)=u(1),
\end{array}\right.
$$

where $1<\alpha \leq 2,0<\xi<1$.

Although the study of fractional BVPs at resonance has acquired fruitful achievements, it should be noted that such problems with Riemann-Stieltjes integrals are very scarce, so it is worthy of further explorations. Riemann-Stieltjes integral has been considered as both multipoint and integral in a single framework, which is more common, see the relevant works due to Ahmad et al. [14-16]. For more details on Riemann-Stieltjes integral and its significance, we refer the reader to the papers by Webb and Infante [17-19] and their other related works. Inspired greatly by the excellent literature mentioned above, in [20], we investigated a fractional differential equation $D_{0_{+}}^{\alpha} u(t)=f(t, u(t))$ with RiemannStieltjes integral $u(0)=u^{\prime}(0)=0, D_{0+}^{\beta} u(1)=\int_{0}^{1} D_{0+}^{\beta} u(t) d A(t)$. By utilizing the monotone iterative method, the sufficient conditions which guarantee the existence of solutions were established. Promoted by [7] and [10], we would change the problem in [20] to make it more complicated so that it could describe more general practical engineering problems. Therefore, we will discuss the following BVP at resonance:

$$
\left\{\begin{array}{l}
D_{0+}^{\alpha} u(t)=f\left(t, u(t), D_{0+}^{\alpha-1} u(t), D_{0+}^{\alpha-2} u(t)\right), \quad t \in(0,1), \\
I_{0^{+}}^{3-\alpha} u(0)=u^{\prime}(0)=0, \quad D_{0+}^{\beta} u(1)=\int_{0}^{1} D_{0+}^{\beta} u(t) d A(t),
\end{array}\right.
$$

among them, $\alpha, \beta$ are real numbers with $2<\alpha \leq 3,0<\beta \leq 1, D_{0+}^{\alpha}$ and $I_{0+}^{\alpha}$ are the RiemannLiouville differentiation and integration criteria, respectively. $f:[0,1] \times \mathbb{R}^{3} \rightarrow \mathbb{R}$ satisfies the Carathéodory conditions, $\int_{0}^{1} D_{0+}^{\beta} u(t) d A(t)$ is a Riemann-Stieltjes integral that satisfies $\int_{0}^{1} t^{\alpha-\beta-1} d A(t)=1$. We wish to pursue some new existence results in this paper by means of the coincidence degree theory of Mawhin. The consequences are fresh and BVP (1.3) is too, so far as we are concerned with researching it for the first time.

For the sake of readers, we will concisely list some necessary symbols now.

Have $Y, Z$ to be real Banach spaces and $L: \operatorname{dom}(L) \subset Y \rightarrow Z$ be a Fredholm mapping satisfied with index zero. Define $P: Y \rightarrow Y, Q: Z \rightarrow Z$ to be continuous projectors with

$$
\begin{aligned}
& \operatorname{Im}(P)=\operatorname{Ker}(L) ; \quad \operatorname{Ker}(Q)=\operatorname{Im}(L) ; \\
& X=\operatorname{Ker}(L) \oplus \operatorname{Ker}(P) ; \quad Z=\operatorname{Im}(L) \oplus \operatorname{Im}(Q),
\end{aligned}
$$


and the isomorphism

$$
\left.L\right|_{\operatorname{dom}(L) \cap \operatorname{Ker}(P)}: \quad \operatorname{dom}(L) \cap \operatorname{Ker}(P) \rightarrow \operatorname{Im}(L)
$$

is reversible. The reversibility of $\left.L\right|_{\operatorname{dom}(L) \cap \operatorname{Ker}(P)}$ is denoted by $K_{P}: \operatorname{Im}(L) \rightarrow \operatorname{dom}(L) \cap \operatorname{Ker}(P)$. Let $\Omega$ be an open bounded subset of $Y$ so that $\operatorname{dom}(L) \cap \Omega \neq \emptyset$. The mapping $N: Y \rightarrow Z$ is called $L$-compact on $\bar{\Omega}$ if $Q N(\bar{\Omega})$ and $K_{P}(I-Q): \bar{\Omega} \rightarrow Y$ are continuous and compact on $\bar{\Omega}$.

The proof of our major results will be shown by employing the coincidence degree theory of Mawhin [21], which plays an extremely important role in investigating the existence of various types of resonant problems. Now, we present it here.

Theorem 1.1 ([21]) Let L be a Fredholm operator of index zero and $N$ be L-compact on the set $\Omega$. Suppose that the following three conditions are satisfied:

(i) $L x \neq \lambda N x$ for each $(x, \lambda) \in[(\operatorname{dom}(L) \backslash \operatorname{Ker}(L)) \cap \partial \Omega] \times(0,1)$;

(ii) $N x \notin \operatorname{Im}(L)$ for each $x \in \operatorname{Ker}(L) \cap \partial \Omega$;

(iii) $\operatorname{deg}\left(\left.J Q N\right|_{\operatorname{Ker}(L)}, \operatorname{Ker}(L) \cap \Omega, \theta\right) \neq 0$, where $Q: Z \rightarrow Z$ is a projection as above with $\operatorname{Im}(L)=\operatorname{Ker}(Q)$ and $J: \operatorname{Im}(Q) \rightarrow \operatorname{Ker}(L)$ is any isomorphism.

Then the operator equation $L x=N x$ has at least one solution in $\operatorname{dom}(L) \cap \bar{\Omega}$.

The remainder of the thesis is organized as follows. Firstly, we list several necessary definitions and lemmas. Secondly, we obtain the solvability for BVP (1.3). Finally, an example is also given to elucidate the major results.

\section{Preliminary lemmas}

Let $C[0,1]$ and $L^{1}[0,1]$ be matched with $\|u\|_{\infty}=\max _{t \in[0,1]}|u(t)|$ and $\|u\|_{1}=\int_{0}^{1}|u(t)| d t$ as their own norms, respectively. Then they are both Banach spaces. For any $n \in N$, have $A C^{n}[0,1]$ to be the space consisting of all functions $u(t)$ with continuous derivatives until $n-1$ order on a closed interval $[0,1]$ such that $u^{n-1}(t)$ is absolutely continuous, which we denote

$$
A C^{n}[0,1]=\left\{u \mid[0,1] \rightarrow \mathbb{R} \text { and } D^{n-1} u(t) \text { is absolutely continuous in }[0,1]\right\} .
$$

Lemma 2.1 ([20]) Assume that the function $y \in C(0,1) \cap L^{1}[0,1]$ and $\alpha, \beta$ are positive constants satisfying $\alpha-\beta \geq 0$. Then

$$
D_{0+}^{\beta} I_{0+}^{\alpha} y(t)=I_{0+}^{\alpha-\beta} y(t)
$$

Now, we present some conclusions owing to Bai [7], which are basal throughout the paper.

Definition $2.2([7])$ Given $\mu>0$ and $N=[\mu]+1$, define a linear space as

$$
C^{\mu}[0,1]=\left\{u \mid u(t)=I_{0_{+}}^{\mu} x(t)+C_{1} t^{\mu-1}+C_{2} t^{\mu-2}+\cdots+C_{N-1} t^{\mu-(N-1)}, t \in[0,1]\right\},
$$

where $C_{i} \in \mathbb{R}, i=1,2, \ldots, N-1$. 
Remark 2.3 ([7]) Built upon functional analysis theory, it follows that $C^{\mu}[0,1]$ is a Banach space endowed with $\|u(t)\|_{C^{\mu}}=\left\|D_{0+}^{\mu} u\right\|_{\infty}+\cdots+\left\|D_{0+}^{\mu-(N-1)} u\right\|_{\infty}+\|u\|_{\infty}$ as its norm.

Lemma 2.4 ([7]) $F \in C^{\mu}[0,1]$ is sequentially compact when it satisfies the characteristics of uniform boundedness and equicontinuity. Here, uniformly bounded connotes that there exists $M>0$ such that, for every $x \in F$,

$$
\|x(t)\|_{C^{\mu}}=\left\|D_{0+}^{\mu} x\right\|_{\infty}+\cdots+\left\|D_{0+}^{\mu-(N-1)} x\right\|_{\infty}+\|x\|_{\infty}<M,
$$

and equicontinuous connotes that for any $\varepsilon>0$, there always exists $\delta>0$ so that

$$
\left|x\left(t_{1}\right)-x\left(t_{2}\right)\right|<\varepsilon \quad\left(\forall t_{1}, t_{2} \in[0,1],\left|t_{1}-t_{2}\right|<\delta, \forall x \in F\right)
$$

and

$$
\left|D_{0+}^{\alpha-i} x\left(t_{1}\right)-D_{0+}^{\alpha-i} x\left(t_{2}\right)\right|<\varepsilon \quad\left(\forall t_{1}, t_{2} \in[0,1],\left|t_{1}-t_{2}\right|<\delta, \forall x \in F, i \in 0,1, \ldots, N-1\right) .
$$

\section{Main results}

Suppose that the following assumptions hold throughout this paper:

(a) $2<\alpha \leq 3,0<\beta \leq 1$ are real numbers;

(b) $\int_{0}^{1} t^{\alpha-\beta-1} d A(t)=1$.

Let $Z=L^{1}[0,1]$ endued with $\|z\|_{1}=\int_{0}^{1}|z(t)| d t$ as its norm. $Y$ can be expressed as

$$
Y=C^{\alpha-1}[0,1]=\left\{u(t) \mid u(t)=I_{0^{+}}^{\alpha-1} u(t), u \in C[0,1], t \in[0,1]\right\}
$$

and equipped with the weighted norm $\|u\|=\left\|D_{0+}^{\alpha-1} u\right\|_{\infty}+\left\|D_{0+}^{\alpha-2} u\right\|_{\infty}+\|u\|_{\infty}$, where $\|u\|_{\infty}:=\sup _{0 \leq t \leq 1}|u(t)|$.

Define $L: \operatorname{dom}(L) \cap Z$ to be the linear operator by

$$
L u=D_{0_{+}}^{\alpha} u(t), \quad u \in \operatorname{dom}(L),
$$

and in which

$$
\begin{aligned}
\operatorname{dom}(L)= & \left\{u \in C^{\alpha-1}[0,1] \mid D_{0_{+}}^{\alpha} u \in C[0,1], I_{0^{+}}^{3-\alpha} u(0)=0, u^{\prime}(0)=0,\right. \\
& \left.D_{0_{+}}^{\beta} u(1)=\int_{0}^{1} D_{0+}^{\beta} u(t) d A(t)\right\} .
\end{aligned}
$$

Define the operator $N: Y \rightarrow Z$ by the formula

$$
N u(t)=f\left(t, u(t), D_{0+}^{\alpha-1} u(t), D_{0+}^{\alpha-2} u(t)\right), \quad t \in[0,1] .
$$

Thus BVP (1.3) transforms to an equivalent operator equation

$$
L u=N u .
$$


Denote

$$
G(t, s)= \begin{cases}{[t(1-s)]^{\alpha-\beta-1}-(t-s)^{\alpha-\beta-1},} & 0 \leq s \leq t \leq 1 \\ {[t(1-s)]^{\alpha-\beta-1},} & 0 \leq t \leq s \leq 1\end{cases}
$$

Lemma 3.1 Let L be delimitated as formula (3.1), then we obtain

$$
\operatorname{Ker}(L)=\left\{u \mid u=c t^{\alpha-1}, c \in R\right\}
$$

and

$$
\operatorname{Im}(L)=\left\{y \in Z \mid \int_{0}^{1}\left(\int_{0}^{1} G(t, s) y(s) d s\right) d A(t)=0\right\}
$$

Proof Direct calculation shows that $D_{0+}^{\alpha} u(t)=0$ has the solution as

$$
u(t)=C_{1} t^{\alpha-1}+C_{2} t^{\alpha-2}+C_{3} t^{\alpha-3}
$$

Due to the BCs $I_{0^{+}}^{3-\alpha} u(0)=u^{\prime}(0)=0$, we get $C_{2}=C_{3}=0$. Moreover, $D_{0+}^{\beta} u(1)=$ $\int_{0}^{1} D_{0+}^{\beta} u(s) d A(s)$ together with $\int_{0}^{1} t^{\alpha-\beta-1} d A(t)=1$ yields that (3.2) is satisfied.

Let $y \in Z$ and

$$
u(t)=-I_{0+}^{\alpha} y(t)+C_{1} t^{\alpha-1} .
$$

In line with Lemma 2.1, we receive

$$
D_{0+}^{\beta} u(t)=-I_{0+}^{\alpha-\beta} y(t)+C_{1} D_{0+}^{\beta} t^{\alpha-1}=-I_{0+}^{\alpha-\beta} y(t)+\frac{C_{1} \Gamma(\alpha)}{\Gamma(\alpha-\beta)} t^{\alpha-\beta-1} .
$$

Substituting the conditions $D_{0+}^{\beta} u(1)=\int_{0}^{1} D_{0+}^{\beta} u(t) d A(t)$ and $\int_{0}^{1} t^{\alpha-\beta-1} d A(t)=1$,

$$
\int_{0}^{1}(1-s)^{\alpha-\beta-1} y(s) d s=\int_{0}^{1}\left(\int_{0}^{t}(t-s)^{\alpha-\beta-1} y(s) d s\right) d A(t)
$$

is available, then we have evidently that

$$
\int_{0}^{1}\left(\int_{0}^{1} t^{\alpha-\beta-1}(1-s)^{\alpha-\beta-1} y(s) d s\right) d A(t)-\int_{0}^{1}\left(\int_{0}^{t}(t-s)^{\alpha-\beta-1} y(s) d s\right) d A(t)=0 .
$$

Consequently, we arrive at (3.3).

Let $u(t)=I_{0^{+}}^{\alpha} y(t)$, then $u \in \operatorname{dom}(L)$ and $D_{0_{+}}^{\alpha} u(t)=y(t)$. Therefore, $y \in \operatorname{Im}(L)$.

Lemma 3.2 The mapping $L: \operatorname{dom}(L) \cap Y \rightarrow Z$ is an index zero Fredholm operator.

Proof Define a subsidiary operator $Q: Z \rightarrow R$ by

$$
Q y=\frac{1}{\int_{0}^{1}\left(\int_{0}^{1} G(t, s) d s\right) d A(t)} \int_{0}^{1}\left(\int_{0}^{1} G(t, s) y(s) d s\right) d A(t)
$$


then

$$
\begin{aligned}
Q^{2} y= & Q(Q y) \\
= & \int_{0}^{1}\left(\int_{0}^{1} G(t, s) d s\right) d A(t) \\
& \quad \times\left(\frac{1}{\int_{0}^{1}\left(\int_{0}^{1} G(t, s) d s\right) d A(t)}\right)^{2} \int_{0}^{1}\left(\int_{0}^{1} G(t, s) y(s) d s\right) d A(t) \\
= & Q y,
\end{aligned}
$$

the above formula shows that $Q: Z \rightarrow Z$ is an idempotent mapping.

Observing that $y \in \operatorname{Im}(L)$, we can get $Q y=\theta$, and then $y \in \operatorname{Ker}(L)$. Otherwise, if $y \in$ $\operatorname{Ker}(Q)$, we may get that $Q y=\theta$, i.e., $y \in \operatorname{Im}(L)$. So, $\operatorname{Ker}(Q)=\operatorname{Im}(L)$.

Denote $y \in Z$ in the way of $y=(y-Q y)+Q y$ so that $y \in Z, Q y \in \operatorname{Im}(L)=\operatorname{Ker}(Q)$ and $Q y \in \operatorname{Im}(Q)$. Thereby, $Z=\operatorname{Im}(L)+\operatorname{Im}(Q)$. In addition, make $y_{0} \in \operatorname{Im}(L) \cap \operatorname{Im}(Q)$ and suppose that $y_{0}(s)=c$ is not identically zero on $[0,1]$. Afterwards, because of $y_{0} \in \operatorname{Im}(L)$, we get $Q\left(y_{0}\right)=Q(c)=c Q(1)=0$ by (3.4) and then derive $c=0$, which is contradictory. Whereupon, $\operatorname{Im}(L) \cap \operatorname{Im}(Q)=0$; thus $Z=\operatorname{Im}(L) \oplus \operatorname{Im}(Q)$. Note that $\operatorname{dim} \operatorname{Ker}(L)=1=\operatorname{codim} \operatorname{Im}(L)$, that is, $L$ is a Fredholm operator of index zero.

Make $P: Y \rightarrow Y$ be defined by

$$
P u(t)=\frac{1}{\Gamma(\alpha)} D_{0+}^{\alpha-1} u(0) t^{\alpha-1} .
$$

Minding that $P$ is a linear continuous mapping and $\operatorname{Ker}(P)=\left\{u \in Y \mid u=D_{0+}^{\alpha-1} u(0)=0\right\}$, it is easy to get the fact $Y=\operatorname{Ker}(L) \oplus \operatorname{Ker}(P)$.

Delimitating $K_{P}: \operatorname{Im}(L) \rightarrow \operatorname{dom}(L) \cap \operatorname{Ker}(P)$ by

$$
K_{P} g(t)=I_{0+}^{\alpha} g(t)
$$

In fact, for $g \in \operatorname{Im}(L),\left(L K_{P}\right) g=g$. At the same time, if $u \in \operatorname{dom}(L) \cap \operatorname{Ker}(P)$, then

$$
\left(K_{P} L g\right)(t)=I_{0+}^{\alpha} D_{0+}^{\alpha} g(t)=g(t)+C_{1} t^{\alpha-1}+C_{2} t^{\alpha-2}+C_{3} t^{\alpha-3},
$$

and based on the BCs of BVP (1.3), we can get that $C_{2}=C_{3}=0$. On the basis of the fact that $g \in \operatorname{dom}(L)$, we derive

$$
D_{0+}^{\alpha-1}\left[K_{P} L g(0)\right]=D_{0+}^{\alpha-1} u(0)+\left.C_{1} D_{0+}^{\alpha-1} t^{\alpha-1}\right|_{t=0},
$$

which shows that $C_{1}=0$. Hence $K_{P}=\left(\left.L\right|_{\operatorname{dom}(L) \cap \operatorname{Ker}(P)}\right)^{-1}$.

Lemma 3.3 Let $\eta=\frac{3}{2}+\frac{1}{\Gamma(\alpha+1)}$. Then

$$
\left\|K_{P} y\right\| \leq \eta\|y\|_{1}
$$

for any $y \in \operatorname{Im}(L)$. 
Proof For each $y \in \operatorname{Im}(L)$ and $t \in[0,1]$, there is

$$
\begin{aligned}
\left\|K_{P} y\right\| & =\left\|I_{0^{+}}^{\alpha} y\right\|=\left\|D_{0^{+}}^{\alpha-2} I_{0^{+}}^{\alpha} y\right\|_{\infty}+\left\|D_{0^{+}}^{\alpha-1} I_{0^{+}}^{\alpha} y\right\|_{\infty}+\left\|I_{0^{+}}^{\alpha} y\right\|_{\infty} \\
& =\left\|I_{0^{+}}^{2} y\right\|_{\infty}+\left\|I_{0^{+}}^{1} y\right\|_{\infty}+\left\|I_{0^{+}}^{\alpha} y\right\|_{\infty} \\
& \leq \frac{t^{2}}{2 \Gamma(2)}\|y\|_{1}+t\|y\|_{1}+\frac{t^{\alpha}}{\Gamma(\alpha+1)}\|y\|_{1} \\
& \leq\left(\frac{3}{2}+\frac{1}{\Gamma(\alpha+1)}\right)\|y\|_{1} .
\end{aligned}
$$

Lemma 3.4 Assume that $f:[0,1] \times \mathbb{R}^{3} \rightarrow \mathbb{R}$ meeting the Carathéodory conditions, then $K_{P}(I-Q) N: Y \rightarrow Y$ is a completely continuous operator.

Proof It is manifested that $K_{P}$ is compact by way of Remark 2.3 and Lemma 2.4. Due to the continuity of $K_{P}, I-Q$ and the boundedness of $N$, the conclusion can be made that this lemma holds.

Theorem 3.5 Let $f:[0,1] \times \mathbb{R}^{3} \rightarrow \mathbb{R}$ meeting the Carathéodory conditions. We impose the following conditions:

$\left(H_{1}\right)$ There exist four functions $a, b, c, r$ which are continuous on $[0,1]$ such that for all $(x, y, z) \in \mathbb{R}^{3}$,

$$
|f(t, x, y, z)| \leq a(t)|x|+b(t)|y|+c(t)|z|+r(t), \quad t \in[0,1]
$$

$\left(H_{2}\right)$ There exists a constant $M>0$ such that for $u \in \operatorname{dom}(L)$, if $\left|D_{0+}^{\alpha-1} u(t)\right|>M$ for all $t \in$ $[0,1]$, then

$$
\int_{0}^{1}\left(\int_{0}^{1} G(t, s) f\left(s, u(s), D_{0+}^{\alpha-1} u(s), D_{0+}^{\alpha-2} u(s)\right) d s\right) d A(t) \neq 0
$$

$\left(H_{3}\right)$ There exists $M^{*}>0$ such that for any $c \in \mathbb{R}$, if $|c|>M^{*}$, afterwards either

$$
c \int_{0}^{1}\left(\int_{0}^{1} G(t, s) f\left(s, c s^{\alpha-1}, c \Gamma(\alpha) s, c \Gamma(\alpha)\right) d s\right) d A(t)<0
$$

or else

$$
c \int_{0}^{1}\left(\int_{0}^{1} G(t, s) f\left(s, c s^{\alpha-1}, c \Gamma(\alpha) s, c \Gamma(\alpha)\right) d s\right) d A(t)>0
$$

$\left(H_{4}\right) \quad 0<\eta \eta_{1}<1$, where $\eta_{1}=\int_{0}^{1}|a(t)| d s+\int_{0}^{1}|b(t)| d s+\int_{0}^{1}|c(t)| d s$.

If hypotheses $\left(H_{1}\right)-\left(H_{4}\right)$ are satisfied, then BVP (1.3) has at least one solution in $\operatorname{dom}(L)$.

Proof Denote $\eta_{2}=\int_{0}^{1}|r(s)| d s$.

Now, the proof will be divided into four steps.

The first step: Deploy $\Omega_{1}=\{u \in \operatorname{dom}(L) \operatorname{Ker}(L) \mid L u=\lambda N u, \lambda \in[0,1]\}$ and prove $\Omega_{1}$ to be a bounded set. Taking $u \in \Omega_{1}$, then $u \in \operatorname{dom}(L) \operatorname{Ker}(L)$ and $L u=\lambda N u$, so $\lambda \neq 0$ and $N u \in$ $\operatorname{Im}(L)=\operatorname{Ker}(Q) \subset Z$. Accordingly, $Q(N u)=\theta$. From $\left(H_{3}\right)$, we have that $\left|D_{0+}^{\alpha-1} u(0)\right| \leq M$. 
Furthermore, for $u \in \Omega_{1}$, we may arrive at

$$
\begin{aligned}
\|P u\|= & \|P u\|_{\infty}+\left\|D_{0+}^{\alpha-1}(P u)\right\|_{\infty}+\left\|D_{0+}^{\alpha-2}(P u)\right\|_{\infty} \\
= & \max _{0 \leq t \leq 1}\left|\frac{1}{\Gamma(\alpha)} D_{0+}^{\alpha-1} u(0) t^{\alpha-1}\right|+\max _{0 \leq t \leq 1}\left|\frac{1}{\Gamma(\alpha)} D_{0+}^{\alpha-1}\left[D_{0+}^{\alpha-1} u(0) t^{\alpha-1}\right]\right| \\
& +\max _{0 \leq t \leq 1}\left|\frac{1}{\Gamma(\alpha)} D_{0+}^{\alpha-2}\left[D_{0+}^{\alpha-1} u(0) t^{\alpha-1}\right]\right| \\
\leq & \left(\frac{1}{\Gamma(\alpha)}+2\right)\left|D_{0+}^{\alpha-1} u(0)\right| \leq\left(\frac{1}{\Gamma(\alpha)}+2\right) M
\end{aligned}
$$

and

$$
\|(I-P) u\|=\left\|K_{P} L(I-P) u\right\| \leq \eta\|L(I-P) u\|_{1}=\eta\|L u\|_{1} \leq \eta\|N u\|_{1} .
$$

It can be seen based on the above discussion that

$$
\|u\|=\|u-P u+P u\| \leq\|P u\|+\|(I-P) u\| \leq\left(\frac{1}{\Gamma(\alpha)}+2\right) M+\eta\|N u\|_{1} .
$$

Under conditions $\left(H_{1}\right)$ and $\left(H_{4}\right)$, for each $u \in \Omega_{1}$, there is

$$
\begin{aligned}
\|N u\|_{1}= & \int_{0}^{1}|(N u)(s)| d s=\int_{0}^{1} f\left(s, u(s), D_{0+}^{\alpha-1} u(s), D_{0+}^{\alpha-2} u(s)\right) d s \\
\leq & \int_{0}^{1}|a(t)| \cdot|u(s)| d s+\int_{0}^{1}|b(t)| \cdot\left|D_{0+}^{\alpha-1} u(s)\right| d s \\
& +\int_{0}^{1}|c(t)| \cdot\left|D_{0+}^{\alpha-2} u(s)\right| d s+\int_{0}^{1}|r(s)| d s \\
\leq & \|u\|_{\infty} \int_{0}^{1}|a(t)| d s+\left\|D_{0+}^{\alpha-1} u\right\|_{\infty} \int_{0}^{1}|b(t)| d s \\
& +\left\|D_{0+}^{\alpha-2} u\right\|_{\infty} \int_{0}^{1}|c(t)| d s+\int_{0}^{1}|r(s)| d s \\
\leq & \|u\| \int_{0}^{1}|a(t)| d s+\|u\| \int_{0}^{1}|b(t)| d s \\
& +\|u\| \int_{0}^{1}|c(t)| d s+\int_{0}^{1}|r(s)| d s .
\end{aligned}
$$

Then, in view of hypothesis $\left(H_{2}\right)$ and the previous formulas (3.5) and (3.6), we may obtain that

$$
\|u\| \leq \frac{\left(\frac{1}{\Gamma(\alpha)}+2\right) M+\eta \eta_{2}}{1-\eta \eta_{1}}
$$

which implies that $\Omega_{1}$ is bounded.

The second step: Let $\Omega_{2}=\{u \in \operatorname{Ker}(L) \mid N u \in \operatorname{Im}(L)\}$. As for $u \in \Omega_{2}$, whereat $u \in \operatorname{Ker}(L)=$ $\left\{u \in \operatorname{dom}(L) \mid u=c t^{\alpha-1}, c \in R, t \in[0,1]\right\}$ and $N u \in \operatorname{Im}(L)$, therefore

$$
\int_{0}^{1}\left(\int_{0}^{1} H(t, s) f\left(s, u(s), D_{0+}^{\alpha-1} u(s)\right) d s, D_{0+}^{\alpha-2} u(s)\right) d A(t)=0 .
$$

It follows from $\left(H_{2}\right)$ that $|c| \leq \frac{M}{\Gamma(\alpha)}$, so $\Omega_{2}$ is bounded in $Y$. 
The third step: Deploy $\Omega_{3}^{(i)}=\left\{u \in \operatorname{Ker}(L) \mid(-1)^{i} \lambda u+(1-\lambda) J Q N u=0, \lambda \in[0,1]\right\}, i=1,2$, we figure out $J: \operatorname{Im}(Q) \rightarrow \operatorname{Ker}(L)$ is a linear isomorphism operator given by $J(c)=c t^{\alpha-1}$. For every $u(t) \in \Omega_{3}^{(1)}$, then $u(t)=c t^{\alpha-1}$,

$$
\lambda c t^{\alpha-1}=(1-\lambda) t^{\alpha-1} \int_{0}^{1}\left(\int_{0}^{1} G(t, s) f\left(s, c s^{\alpha-1}, c \Gamma(\alpha) s, c \Gamma(\alpha)\right) d s\right) d A(t),
$$

so

$$
\lambda c^{2}=(1-\lambda) c \int_{0}^{1}\left(\int_{0}^{1} G(t, s) f\left(s, c s^{\alpha-1}, c \Gamma(\alpha) s, c \Gamma(\alpha)\right) d s\right) d A(t) .
$$

When $\lambda=1, c=0$ is available. Elsewise, if $|c|>M^{*}$, on the basis of the initial part of condition $\left(H_{3}\right)$, we obtain

$$
c \int_{0}^{1}\left(\int_{0}^{1} G(t, s) f\left(s, c s^{\alpha-1}, c \Gamma(\alpha) s, c \Gamma(\alpha)\right) d s\right) d A(t)<0,
$$

which contradicts $\lambda c^{2} \geq 0$. Thus this means we have verified that $\Omega_{3}^{(1)} \in\{u \in \operatorname{Ker}(L) \mid u \in$ $\left.c t^{\alpha-1},|c| \leq M^{*}\right\}$ is a bounded set in $Y$.

Analogous to the above discussion, we may arrive at $\Omega_{3}^{(2)}$ is bounded too.

The last step: Set $\Omega$ to be an open bounded set in $Y$ so that $\Omega \supset \Omega_{1} \cup \Omega_{2} \cup \Omega_{3}^{(i)}, i=1,2$, and prove that

$$
\operatorname{deg}\left(\left.J Q N\right|_{\operatorname{Ker}(L)}, \operatorname{Ker}(L) \cap \Omega, \theta\right) \neq 0 .
$$

The operator $N$ is $L$-compact on $\bar{\Omega}$ according to the conclusion that $Q N(\bar{\Omega})$ is bounded and $K_{P}(I-Q) N: Y \rightarrow Y$ is completely continuous. Thus, with the first two steps, we may obtain

(i) $L x \neq \lambda N x$ for every $(x, \lambda) \in[(\operatorname{dom}(L) \operatorname{Ker}(L)) \cap \partial \Omega] \times(0,1)$;

(ii) $N x \notin \operatorname{Im}(L)$ for every $x \in \operatorname{Ker}(L) \cap \partial \Omega$.

Define $H(u, \lambda)=(-1)^{i} \lambda I u+(1-\lambda) J Q N u, i=1,2$, in which $I$ is the identity mapping in $X$. In line with the discussions in the third step, we know that

$$
H(u, \lambda) \neq 0, \quad \text { for any } u \in \operatorname{Ker}(L) \cap \partial \Omega,
$$

and then, for $i=1,2$, utilizing the degree property of invariance under a homotopy, we can arrive at

$$
\begin{aligned}
\operatorname{deg}\left(\left.J Q N\right|_{\operatorname{Ker}(L)}, \operatorname{Ker}(L) \cap \Omega, \theta\right) & =\operatorname{deg}(H(\cdot, 0), \operatorname{Ker}(L) \cap \Omega, \theta) \\
& =\operatorname{deg}(H(\cdot, 1), \operatorname{Ker}(L) \cap \Omega, \theta) \\
& =\operatorname{deg}\left((-1)^{i} I, \operatorname{Ker}(L) \cap \Omega, \theta\right) \\
& =(-1)^{i} \neq 0,
\end{aligned}
$$

which certifies condition (iii) of Theorem 1.1.

In sum, all hypotheses of Theorem 1.1 are met. Thereby, BVP (1.3) has at least one solution in $\operatorname{dom}(L) \cap \bar{\Omega}$. 


\section{Example}

In this section, an example is given to elucidate the accuracy of the main results.

Consider the BVP

$$
\left\{\begin{array}{l}
D_{0_{+}}^{\frac{5}{2}} u(t)=f\left(t, u(t), D_{0+}^{\frac{3}{2}} u(t), D_{0_{+}}^{\frac{1}{2}} u(t)\right), \quad t \in(0,1), \\
I_{0^{+}}^{\frac{1}{2}} u(0)=u^{\prime}(0)=0, \quad D_{0_{+}}^{\frac{1}{2}} u(1)=\int_{0}^{1} D_{0_{+}}^{\frac{1}{2}} u(t) d A(t),
\end{array}\right.
$$

where $\alpha=\frac{5}{2}, \beta=\frac{1}{2}, A(t)=t$, and

$$
f(t, x, y, z)=a(t) \frac{\sin x}{2}+b(t) \frac{e^{-|y|}}{2}+\frac{z}{2}+\gamma(t), \quad(x, y, z) \in R
$$

and

$$
a(t)=\frac{1}{1+t^{2}}, \quad b(t)=\frac{1}{1+t}, \quad c(t)=\frac{1}{1+t^{3}}, \quad \gamma(t)=\cos ^{2} t, \quad t \in[0,1] .
$$

Condition $\left(H_{1}\right)$ holds obviously. We choose $M=2$ and assume $\left|D_{0+}^{\frac{3}{2}} u\right|>M$ holds for any $t \in[0,1]$. On the one hand, if $D_{0+}^{\frac{3}{2}} u(t)>M$ holds for any $t \in[0,1]$, then

$$
f\left(t, u(t), D_{0+}^{\frac{3}{2}} u(t), D_{0+}^{\frac{1}{2}} u(t)\right) \geq \frac{M-1}{2}>0
$$

so

$$
\begin{aligned}
& \int_{0}^{1}\left(\int_{0}^{1} t(1-s) f\left(t, u(t), D_{0+}^{\frac{3}{2}} u(t), D_{0+}^{\frac{1}{2}} u(t)\right) d s\right) d t \\
& \quad-\int_{0}^{1}\left(\int_{0}^{t}(t-s) f\left(t, u(t), D_{0+}^{\frac{3}{2}} u(t), D_{0+}^{\frac{1}{2}} u(t)\right) d s\right) d t \\
& \geq \int_{0}^{1}\left(\int_{0}^{1}(t(1-s)-(t-s)) f\left(t, u(t), D_{0+}^{\frac{3}{2}} u(t), D_{0+}^{\frac{1}{2}} u(t)\right) d s\right) d t \\
& \geq \frac{M-1}{24}>0 .
\end{aligned}
$$

On the other hand, if $D_{0+}^{\frac{3}{2}} u(t)<-M$ holds for any $t \in[0,1]$, then

$$
f\left(t, u(t), D_{0+}^{\frac{3}{2}} u(t), D_{0+}^{\frac{1}{2}} u(t)\right) \leq 1-M<0,
$$

so

$$
\begin{aligned}
& \int_{0}^{1}\left(\int_{0}^{1} t(1-s) f\left(t, u(t), D_{0+}^{\frac{3}{2}} u(t), D_{0+}^{\frac{1}{2}} u(t)\right) d s\right) d t \\
& \quad-\int_{0}^{1}\left(\int_{0}^{t}(t-s) f\left(t, u(t), D_{0+}^{\frac{3}{2}} u(t), D_{0+}^{\frac{1}{2}} u(t)\right) d s\right) d t \\
& \quad \leq \int_{0}^{1}\left(\int_{0}^{1} t(1-s) f\left(t, u(t), D_{0+}^{\frac{3}{2}} u(t), D_{0+}^{\frac{1}{2}} u(t)\right) d s\right) d t \\
& \quad<(1-M) \int_{0}^{1}\left(\int_{0}^{1} t(1-s) d s\right) d t<0 .
\end{aligned}
$$


Thus, condition $\left(H_{2}\right)$ is established. Again, taking $M^{*}=2$, for any $c \in R$, if $|c|>M^{*}$, we have

$$
\begin{aligned}
c\left[\int_{0}^{1}\left(\int_{0}^{1} t(1-s) f\left(s, c s^{\frac{3}{2}}, c \Gamma\left(\frac{5}{2}\right) s, c \Gamma\left(\frac{5}{2}\right)\right) d s\right) d t\right. \\
\left.\quad-\int_{0}^{1}\left(\int_{0}^{t}(t-s) f\left(s, c s^{\frac{3}{2}}, c \Gamma\left(\frac{5}{2}\right) s, c \Gamma\left(\frac{5}{2}\right)\right) d s\right) d t\right]<0 .
\end{aligned}
$$

So, condition $\left(H_{3}\right)$ is established. Consequently, by Theorem 3.5, BVP (4.1) has at least one positive solution.

\section{Acknowledgements}

The thesis is funded by the Educational Science Research Project of Tangshan University (170322) and the Backbone teachers' Cultivating Program of Tangshan University. The author would like to thank the anonymous referees very much for helpful comments and suggestions which led to the improvement of presentation and quality of the work.

\section{Competing interests}

The author declares that they have no competing interests.

\section{Authors' contributions}

The main idea of this paper was proposed by H-EZ. She prepared the manuscript initially and performed all the steps of the proofs in this research. The author read and approved the final manuscript.

\section{Publisher's Note}

Springer Nature remains neutral with regard to jurisdictional claims in published maps and institutional affiliations.

Received: 2 February 2017 Accepted: 26 September 2017 Published online: 13 October 2017

\section{References}

1. Kilbas, AA, Srivastava, HM, Trujillo, JJ: Theory and Applications of Fractional Differential Equations. North-Holland Mathematics Studies, vol. 204. Elsevier, Amsterdam (2006)

2. Miller, KS, Ross, B: An Introduction to the Fractional Calculus and Fractional Differential Equation. Wiley, New York (1993)

3. Podlubny, I: Fractional Differential Equations, Mathematics in Science and Engineering. Academic Press, New York (1999)

4. Nonnenmacher, TF, Metzler, R: On the Riemann-Liouville fractional calculus and some recent applications. Fractals 3, 557-566 (1995)

5. Bai, ZB, Zhang, YH: Solvability of fractional three-point boundary value problems with nonlinear growth. Appl. Math. Comput. 218(5), 1719-1725 (2011)

6. Bai, ZB: On solutions of some fractional m-point boundary value problems at resonance. Electron. J. Qual. Theory Differ. Equ. 2010, 37 (2010)

7. Bai, ZB: Solvability for a class of fractional m-point boundary value problem at resonance. Comput. Math. Appl. 62, 1292-1302 (2011)

8. Infante, G, Zima, M: Positive solutions of multi-point boundary value problems at resonance. Nonlinear Anal. 69 2458-2465 (2008)

9. Jiang, W: The existence of solutions to boundary value problems of fractional differential equations at resonances. Nonlinear Anal. 74, 1987-1994 (2011)

10. Kosmatov, N: A boundary value problem of fractional order at resonance. Electron. J. Differ. Equ. 135, 1 (2010)

11. Liang, SQ, Mu, L: Multiplicity of positive solutions for singular three-point boundary value problem at resonance. Nonlinear Anal. 71, 2497-2505 (2009)

12. Zhang, HE, Sun, JP: Positive solutions of third-order nonlocal boundary value problems at resonance. Bound. Value Probl. 2012, 102 (2012)

13. Zhang, Y, Bai, ZB, Feng, T: Existence results for a coupled system of nonlinear fractional three-point boundary value problems at resonance. Comput. Math. Appl. 61, 1032-1047 (2011)

14. Bashir, A, Ntouyas, SK: Nonlocal fractional boundary value problems with slit-strips boundary conditions. Fract. Calc. Appl. Anal. 18, 261-280 (2015)

15. Garout, D, Ahmad, B, Alsaedi, A: Existence theorems for semi-linear Caputo fractional differential equations with nonlocal discrete and integral boundary conditions. Fract. Calc. Appl. Anal. 19, 463-479 (2016)

16. Agarwal, RP, Ahmad, B, Garout, D, Alsaedi, A: Existence results for coupled nonlinear fractional differential equations equipped with nonlocal coupled flux and multi-point boundary conditions. Chaos Solitons Fractals (2017). doi:10.1016/j.chaos.2017.03.025

17. Webb, JRL, Infante, G: Positive solutions of nonlocal boundary value problems: a unified approach. J. Lond. Math. Soc (2) 74, 673-693 (2006)

18. Webb, JRL, Infante, G: Nonlocal boundary value problems of arbitrary order. J. Lond. Math. Soc. (2) 79, $238-258$ (2009) 
19. Webb, JRL: Positive solutions of some higher order nonlocal boundary value problems. Electron. J. Qual. Theory Differ. Equ. 29, 1 (2009)

20. Zhang, HE: Iterative solutions for fractional nonlocal boundary value problems involving integral conditions. Bound. Value Probl. 2016, 3 (2016)

21. Mawhin, J: Topological Degree Methods in Nonlinear Boundary Value Problems. NSFCBMS Regional Conference Series in Mathematics. Am. Math. Soc., Providence (1979)

Submit your manuscript to a SpringerOpen ${ }^{\mathcal{O}}$ journal and benefit from:

- Convenient online submission

- Rigorous peer review

- Open access: articles freely available online

- High visibility within the field

- Retaining the copyright to your article

Submit your next manuscript at $\gg$ springeropen.com 